\title{
Comparative effectiveness of Dimethyl Sulphoxide (DMSO) and Glycerol as cryoprotective agent in preserving Vero cells
}

\author{
MSI Siddiqui, M Giasuddin ${ }^{1}, \mathrm{SMZH}$ Chowdhury ${ }^{2}, \mathrm{MR}$ Islam and EH \\ Chowdhury* \\ Department of Pathology, Faculty of Veterinary Science, Bangladesh Agricultural \\ University, Mymensingh-2202, Bangladesh
}

\begin{abstract}
Vero cells have been derived from the kidney of African green monkeys (Cercopithecus aethiops) as mammalian continuous cell lines for biological research. Continuous culturing of Vero cells as well as maintenance of frozen stock is important for future use. Dimethyl sulphoxide (DMSO) and glycerol are two common cryoprotectants used widely to maintain frozen cell lines. DMSO, as a cryoprotectant in cryopreservation procedures, is detrimental to cells. A study was carried out to compare the effect of DMSO and glycerol as cryoprotectants on Vero cells. Vero cells were cultured and maintained using same nutrients and environment, following the modified protocol of Ammerman et al. (2008). After total cell counting the Vero cells were preserved in Cryocane at liquid nitrogen temperature $\left(-196^{\circ} \mathrm{C}\right)$. Two frozen stocks were made simultaneously from the cell suspensions of same concentrations using DMSO and glycerol. After one year of preservation post-thawed cell viability with glycerol was higher than with DMSO. Solutions of $10 \%$ glycerol could be the best choice as cryoprotectant for long-term (1 year) preservation of Vero cells. (Bangl. vet. 2015. Vol. 32, No. 2, 35 - 41)
\end{abstract}

\section{Introduction}

Vero cells were originally isolated from the kidney of healthy adult African green monkeys (Cercopithecus aethiops) in 1962 by Y. Yasumura and Y. Kawakita at the Chiba University in Chiba, Japan. By the end of the 1960s, Vero cell lines were being used across the globe, primarily in virology laboratories. Vero cells are one of the most common mammalian continuous cell lines used in biological research. This anchorage-dependent cell line has been used extensively in virology, and in the propagation and study of intracellular bacteria (e.g., Rickettsia spp.; UNIT 3A.4) and parasites (e.g., Neospora), and assessment of the effects of chemicals, toxins and other substances on mammalian cells at the molecular level. Vero cells have been licensed in the United States for production of live (rotavirus, smallpox) and inactivated (poliovirus) viral vaccines, and throughout the world Vero cells have been used for the production of other viruses, including Rabies virus, Reovirus and Japanese encephalitis virus. There are several lines of Vero cells commercially available (e.g., Vero, Vero 76, Vero E6), all ultimately derived from the same source.

\footnotetext{
1Bangladesh Livestock Research Institute, Savar, Dhaka, Bangladesh

${ }^{2}$ Bangladesh Agricultural Research Council, Farmgate, Dhaka, Bangladesh

*Corresponding author:- E-mail: emdad001@yahoo.com
} 
Maintenance of frozen stocks is extremely important when culturing cell lines. When actively growing cells are not required for three weeks or more, keeping frozen stocks allows researchers to discontinue regular sub-culturing (Lieu et al., 2007; Xiang et al., 2007). In order to maintain an inventory of low-subculture Vero cells, new frozen stocks should be prepared shortly after initiating cultures from frozen stocks. Techniques are available for the cryopreservation of microorganisms, tissues, primary cells, established cell lines, small multicellular organisms, embryos, as well as nucleic acid and proteins (Mazur, 1984; Rall, 1987; Simione and Brown, 1991). Many compounds have been tried as cryoprotective agents, including sugars, solvents and even serum. DMSO and glycerol have been widely used and demonstrated to be the most effective agents for preserving living cells and organisms (Areman et al., 1990; Lee et al., 2005; Fleming and Hubel, 2006). Other cryoprotectants include polyethylene glycol, propylene glycol, polyvinylpyrolidone, sorbitol, dextran and trehalose (Loken and Demetrick, 2005; Buchanan et al., 2005).

DMSO is the most frequently used cryoprotectant in research and clinical purposes. However, there is no consensus on its optimal concentration. Defining the right concentration is important, because DMSO can cause severe adverse reactions. The recent trend is reducing DMSO concentration and/or replacing DMSO by other nontoxic cryoprotectants. About $10 \%$ of DMSO is widely used, but some centres have started to test lower DMSO concentrations.

Glycerol acts by retaining water within the cell, avoiding excessive dehydration due to the exposure to concentrated solutions. Higher concentrations of glycerol are most protective (Mazur and Kleinhan, 2008). On the other hand cryoprotectant toxicity has been claimed to be the limiting factor for the success of cryopreservation (Fahy, 2010). To freeze mammalian sperms glycerol is the most widely used cryoprotectant, however glycerol may have toxic effects on the spermatozoa in a dose-dependent manner (Meryman, 1971). Equine semen is frozen using glycerol at concentrations ranging from 2 to 5\% (Loomis et al., 1983; Vidament et al., 2000; Loomis and Graham 2008), however few controlled studies have addressed the toxicity of different concentrations of glycerol (Gao, 1992; Ball and Vo, 2001). The nature of the cryoprotective agent and the freezing process are important factors affecting the recovery of cryopreserved mammalian cells (Baust, 2002). This study has been conducted to find a suitable cryoprotective agent for the long-term cryopreservation of Vero cells as well as enhancement of their recovery.

\section{Materials and Methods}

\section{Cell line}

Vero cell line (CLS, Germany) was bought from commercial source.

\section{Cell culture media and reagents}

Cell culture medium-M-1999 (Gibco-Invitrogen, cat no. 11825), calf serum-FBS (GibcoInvitrogen, cat no. 10437), 0.25\% Trypsin with EDTA (Gibco-Life technologies 20367, C13), DMSO (Gibco-Life technologies), glycerol were used. 


\section{Cell counting}

Vero cells were counted using haemocytometer with $0.4 \%$ trypan blue dye solution.

\section{Growth and maintenance of Vero cells}

Continuous Vero cell culture and subculture were performed according to a modified protocol of Ammerman et al. (2009). Briefly, when $80-100 \%$ confluence was achieved in the cell cultures, medium in the cell culture flasks was carefully removed with a pipette and washed once with sterilized phosphate-buffered saline (PBS) (Sigma Aldrich). Then, $1 \mathrm{~mL}$ of $0.25 \%$ Trypsin-EDTA solution (Gibco-Life technologies 20367, C13) was added to detach the cell monolayer. Then, $0.5 \mathrm{~mL}$ of $50 \%$ FBS was added to terminate trypsinisation. The cell suspensions were centrifuged at $3000 \mathrm{rpm}$ for 10 min, and the supernatant removed. The harvested cells were re-suspended with M199 medium plus 10\% FBS and 2\% penicillin- streptomycin solution. Seven successive subcultures were performed to obtain a relatively strong pure cell.

\section{Cryopreservation of Vero cells with DMSO and glycerol}

Vero cells in the logarithmic growth phase ( $80 \%-90 \%$ confluence) were harvested by rinsing the cell sheet three times with sterilized phosphate-buffered saline (PBS: Sigma Aldrich), after which $01 \mathrm{~mL}$ of $0.25 \%$ trypsin- EDTA solution (Gibco-Life technologies 20367, C13) was added. Flasks were examined under a phase contrast inverted microscope (Olympus, CK2-TR, Japan) at $37^{\circ} \mathrm{C}$ for $20-30 \mathrm{sec}$. The flasks were shaken gently to detach the cells, and $10 \%$ FBS was added to terminate trypsinisation. Cell suspensions were centrifuged at $3000 \mathrm{rpm}$ for $10 \mathrm{~min}$, and the supernatant was removed. The harvested cells were re-suspended with freezing medium containing $10 \%$ FBS, 10\% DMSO (Sigma, USA) or 10\% glycerol and 80\% M-199 and reached a final concentration of $1-2 \times 10^{6}$ viable cells $/ \mathrm{mL}$. The re-suspended cells were counted using a haemocytometer and dispensed into $2.0 \mathrm{~mL}$ cryogenic vials (Corning). DMSO-preserved cryogenic vials were transferred directly into liquid nitrogen and glycerol-preserved vials were kept first at $2-8^{\circ} \mathrm{C}$ for $3-4$ hours, then at $80^{\circ} \mathrm{C}$ overnight and finally stored in liquid nitrogen.

\section{Thawing of Vero cell lines}

To recover and reseed the cells, the cryogenic vials were removed from the liquid nitrogen after one year of cryopreservation and quickly thawed in a $37^{\circ} \mathrm{C}$ water bath. The thawed cells were transferred to $25 \mathrm{sq}-\mathrm{cm}$ cell culture flask (Corning), and $5 \mathrm{~mL}$ M-199 media was added slowly to equilibrate and exchange the DMSO or glycerol within 2 to $3 \mathrm{~min}$. After centrifugation at $3000 \mathrm{rpm}$ for $5 \mathrm{~min}$, the pellet was re-suspended gently in M-199 media containing 20\% FBS and 2\% penicillinstreptomycin solution and cultured at $37^{\circ} \mathrm{C}$ in $5 \% \mathrm{CO}_{2}$ and $100 \%$ humidity.

\section{Cell viability analysis by Trypan Blue Exclusion Test}

A cell viability analysis was performed using the trypan blue dye exclusion staining method of Anjomshoa et al. (2009). Vero cells cryopreserved with DMSO or glycerol 
were mixed with an equal volume of $0.4 \%$ trypan blue dye solution (LEA Gene Biotech, China) immediately after thawing. Approximately $20 \mathrm{ml}$ of the cell mixture was transferred to both sides of the haemocytometer, covered with a cover glass, and observed under light microscopy. The numbers of dead and viable cells were recorded based on the development of blue colour. Survival rate of Vero cells was calculated using the formula:

Cells viability $=\frac{\text { Number of viable cells }(\text { unstained cells })}{\text { Total cell number }(\text { stained }+ \text { unstained cells })} \times 100$

\section{Statistical analysis}

The data of live cells count were analysed using $t$-test.

\section{Results and Discussion}

A total of 40 vials containing preserved Vero cells (20 preserved with $10 \%$ DMSO and 20 with $10 \%$ glycerol) were used to determine post-thawing viability. In case of $10 \%$ DMSO viability was $60 \%$ whereas in case of glycerol $70 \%$ (Table 1 ). The difference might be due to less toxic effect of glycerol than DMSO on Vero cells.

Table 1. Post-thawing viability of Vero cells

\begin{tabular}{l|c|c|c|c}
\hline $\begin{array}{c}\text { Cryoprotective } \\
\text { agent }\end{array}$ & $\begin{array}{c}\text { Total no. of vials } \\
\text { containing Vero } \\
\text { cells }\end{array}$ & $\begin{array}{c}\text { No. of vials } \\
\text { containing Vero } \\
\text { cells (not revived) }\end{array}$ & $\begin{array}{c}\text { No. of vials } \\
\text { containing cells } \\
\text { (revived) }\end{array}$ & $\begin{array}{c}\text { Post-thawing } \\
\text { viability (\%) }\end{array}$ \\
\hline $10 \%$ glycerol & 20 & 06 & 14 & 70 \\
$10 \%$ DMSO & 20 & 08 & 12 & 60 \\
\hline
\end{tabular}

The cell viability was $14.6 \%$ more in case of glycerol than DMSO (Table 2$)(\mathrm{P}<0.05)$ similar to the findings by Durrani et al. (2015) in a study using 10\% DMSO for longterm storage of BHK-21 cells. The result is dissimilar to the findings of Merten et al. (1995) who developed a serum-free medium to which $10 \%$ DMSO and $0.1 \%$ methylcellulose or 3\% polyvinyl pyrrolidone were added, for the cryopreservation of animal cells.

Table 2. Percentage of live and dead Vero cells after recovery from cryopreservation using DMSO or glycerol

\begin{tabular}{l|c}
\hline \multicolumn{1}{c|}{ Cryoprotective agent } & Cell viability \\
\hline $10 \%$ DMSO & $74 \%$ \\
$10 \%$ glycerol & $88.6 \%$ \\
\hline
\end{tabular}

The cell viability in case of glycerol was $88.6 \%$. Very few similar studies have been conducted, but $10 \%$ glycerol was extensively used in a study conducted by Visintin et al. (2000) for cryopreservation of rat morulae: embryos were cultured in Whitten's 
medium at $37^{\circ} \mathrm{C}, 5 \% \mathrm{CO}_{2}$ and $100 \%$ humidity; the in vitro development ranged from $56.6 \%$ to $100 \%$ after 72 hours of incubation. Effect of glycerol and dimethyl sulfoxide on cryopreservation of rhesus monkey (Macaca mulatta) sperm was evaluated by $\mathrm{Si}$ et al. (2004) where 5\% glycerol was better than 5\% DMSO. It was found that spermatozoa cryopreserved with 15\% DMSO showed the lowest post-thaw sperm motility, and spermatozoa cryopreserved with 15\% glycerol and 15\% DMSO showed the lowest plasma membrane integrity. In contrast, Feradis et al. (2001) found that glycerol and DMSO at $6 \%$ concentration produced equivalent survival rates of cynomolgus epididymal sperm after cryopreservation. Lusianti et al. (2013) observed that storage of red blood cells (RBCs) in a refrigerated state allowed a shelf-life of a few weeks, whereas RBCs frozen in $40 \%$ glycerol had a shelf-life of 10 years.

DMSO above $4^{\circ} \mathrm{C}$ has a toxic effect on mammalian cells: that is why cryopreserved cells should be re-suspended as soon as possible after thawing at $37^{\circ} \mathrm{C}$ to reduce the adverse effect of DMSO, such adverse effects of DMSO might play an important role in cell viability during cell counting. The toxicity of glycerol apparently is related to osmotic and non-osmotic effects. Glycerol exerted toxicity at concentrations of 3.5\% or more: the maximal toxicity was observed at $5 \%$ in cryopreservation of stallion spermatozoa (Garcia et al., 2012) but data in regard to Vero cells was not available. Although there may be some variation within a given lot, with constant storage conditions the number of recovered cells will generally be the same in all vials. Vialto-vial variation may be an indication of problems occurring during storage and handling, which hamper cell viability, though this was not considered. Another factor that can affect the recovery of cryopreserved Vero cells was the freezing process. The slow freezing protocol in case of glycerol preservation might improve Vero cell viability.

Glycerol has been used widely as a cryoprotectant for mammalian sperm cells but has not been used frequently to preserve other mammalian cells like Vero or BHK. BHK or Vero cells are genetically mutated, and less sensitive than sperm cells. Glycerol is cheaper and more available than DMSO in Bangladesh. Therefore, glycerol could be as effective as DMSO for the long-term preservation of Vero cells in liquid nitrogen.

\section{References}

Ammerman NC, Beier-Sexton M, Azad FA 2009: Growth and Maintenance of Vero Cell Lines. Current Protocol of Microbiology, November; APPENDIX: Appendix-4E. doi:10.1002/9780471729259.mca04es11.

Anjomshoa M, Karbalaie K, Mardani M, Razavi S, Tanhaei S, Nasr-Esfahani MH, Baharvand H 2009: Generation of motor neurons by coculture of retinoic acidpretreated embryonic stem cells with chicken notochords. Stem Cells Development $\mathbf{1 8}$ 259-267.

Areman EM, Sacher A, Deeg HJ 1990: Cryopreservation and storage of human bone marrow: A survey of current practices. Progress of Clinical and Biological Research 333 523-529. 
Ball BA, Vo A 2001: Osmotic tolerance of equine spermatozoa and the effects of soluble cryoprotectants on equine sperm motility, viability, and mitochondrial membrane potential. Journal of Andrology 22 1061-1069.

Buchanan SS, Menze MA, Hand SC, Pyatt DW, Carpenter JF 2005: Cryopreservation of human hematopoietic stem and progenitor cells loaded with trehalose: transient permeabilization via the adenosine triphosphate-dependent P2Z receptor channel. Cell Preservation Technology 3 212-222.

Baust JM 2002: Molecular mechanisms of cellular demise associated with cryopreservation failure. Cell Preservation Technology 1 17-31.

Durrani A, Mirza A, Khan ZH, Khan N, Kulkarni SS, Yusuf AA 2015: Adaptation of mammalian cell from $10 \%$ serum medium to serum free or low serum media. International Journal of Applied Research 1770 -772.

Fahy GM 2010: Cryoprotectant toxicity neutralization. Cryobiology 60 45-53.

Feradis AH, Pawitri D, Suatha IK, Amin MR, Yusuf TL, Sajuthi D, Budiarsa IN, Hayes ES 2001: Cryopreservation of epididymal spermatozoa collected by needle biopsy from cynomolgus monkeys (Macaca fascicularis). Journal of Medical Primatology 30 100-106.

Fleming KK, Hubel A 2006: Cryopreservation of hematopoietic and non-hematopoietic stem cells. Transfusion and Apheresis Science 34 309-315.

Garcia BM, Ferrusola CO, Aparicio IM, Miro-Moran A, Rodriguez AM, Bolanos JM, Fernandez LG, Balao da Silva CM, Martinez HR, Tapia JA, J Pena FJ 2012: Toxicity of glycerol for the stallion spermatozoa: Effects on membrane integrity and cytoskeleton, lipid peroxidation and mitochondrial membrane potential. Theriogenology 777.

Gao DY, Mazur P, Kleinhans FW, Watson PF, Noiles EE, Critser JK 1992: Glycerol permeability of human spermatozoa and its activation energy. Cryobiology 29 657-667.

Loken SD, Demetrick DJ 2005: A novel method for freezing and storing research tissue bank specimens. Human Pathology 36 977-980.

Lusianti RE, Benson JD, Acker JP, Higgins AZ 2013: Rapid Removal of Glycerol from Frozen-Thawed Red Blood Cells. Biotechnology Progress 29 609-620.

Lee MW, Yang MS, Park JS, Kim HC, Kim YJ, Choi J 2005: Isolation of mesenchymal stem cells from cryopreserved human umbilical cord blood. International Journal of Hematology 81 126-130.

Lieu G, Zhao L, Cui L, Liu W, Cao Y 2007: Tissue-engineered bone formation using human bone marrow stromal and novel beta-tricalcium phosphate. Biomedical Materials 2 78-86.

Loomis PR, Amann RP, Squires EL, Pickett BW 1983: Fertility of unfrozen and frozen stallion spermatozoa extended in EDTA-lactose-egg yolk and packaged in straws. Journal of Animal Science 156 687-693. 
Loomis PR, Graham JK 2008: Commercial semen freezing: individual male variation in cryosurvival and the response of stallion sperm to customized freezing protocols. Animal Reproduction Science 105 119-128.

Mazur P, Kleinhans FW 2008: Relationship between intracellular ice formation in oocytes of the mouse and Xenopus and the physical state of the external medium--a revisit. Cryobiology 56 22-27.

Merten OW, Petres S, Couvé E 1995: A Simple Serum-free Freezing Medium for Serumfree Cultured Cells. Biologicals 23 185-189.

Meryman HT 1971: Cryoprotective agents. Cryobiology 8 173-183.

Mazur P 1984: Freezing of living cells: mechanisms and implications. American Journal of Physiology 247 125-142.

Rall WF 1987: Factors affecting the survival of mouse embryos cryopreserved by vitrification. Cryobiology 24 387-402.

Simione EFP, Brown EM 1991: ATCC Preservation Methods: Freezing and Freeze Drying. American Type Culture Collection, Rockville, Maryland.

Si W, Zheng P, li Y, Dinnyes A, Ji W 2004: Effect of Glycerol and Dimethyl Sulfoxide on Cryopreservation of Rhesus Monkey (Macaca mulatta) Sperm. American Journal of Primatology 62 301-306.

Vidament M, Ecot P, Noue P, Bourgeois C, Magistrini M, Palmer E 2000: Centrifugation and addition of glycerol at 22 degrees $C$ instead of 4 degrees $C$ improve post-thaw motility and fertility of stallion spermatozoa. Theriogenology 54 907-919.

Visintin JA, Garcia JF, Pantano J, D'ávila d Assumpção MEO 2000: Cryopreservation of mouse morulae in glycerol, sucrose and honeybee royal jelly Brazilian Journal of Veterinary Research and Animal Science 37 http://dx.doi.org/10.1590/S141395962000000400009 .

Xiang Y, Zheng Q, Jia B, Huang G, Xie C, Pan J, Wang J 2007: Ex vivo expansion, adipogenesis and neurogenesis of cryopreserved human bone marrow mesenchymal stem cells. Cell Biology International 31 444-450.

Yasumura and Kawakita 1963: Studies on SV40 in tissue culture-preliminary step for cancer research "in vitro." Nihon Rinsho 21 1201-1215. 